\title{
El vino en los cuidados al enfermo en Portugal de 1701 a 1800
}

\section{Wine in the care of the sick in Portugal from 1701 to 1800}

\section{O vinho nos cuidados ao enfermo no Portugal de 1701 a} 1800

\author{
Cristina Lavareda Baixinhoํㅜㄹ Isabel Ferraz Pereira² ${ }^{2}$ Óscar Ramos \\ Ferreira $^{3}$, Helga Rafael Henriques ${ }^{4}$ \\ ${ }^{1}$ Doutora em Enfermagem. Especialista em Enfermagem de Reabilitação. Docente na Escola Superior de \\ Enfermagem de Lisboa, Portugal. \\ ${ }^{2}$ Doutora em Enfermagem. Especialista em Enfermagem Médico-cirúrgica. Docente na Escola Superior \\ de Enfermagem de Lisboa, Portugal. \\ ${ }^{3}$ Doutor em Educação, Especialidade de História da Educação, Especialista em Enfermagem Médico- \\ Cirúrgica. Docente na Escola Superior de Enfermagem de Lisboa, Portugal. \\ ${ }^{4}$ Doutora em Enfermagem. Especialista em Enfermagem em Enfermagem Médico-cirúrgica. Docente na \\ Escola Superior de Enfermagem de Lisboa, Portugal. \\ Cómo citar este artículo en edición digital: Baixinho, C.L., Pereira, I.F., Ferreira, O.M.R. \& Rafael, \\ H.H. (2018). El vino en los cuidados al enfermo en Portugal de 1701 a 1800. Cultura de los Cuidados \\ (Edición digital), 22(52). Recuperado de http://dx.doi.org/10.14198/cuid.2018.52.08 \\ Correspondencia: Cristina Lavareda Baixinho. Rua dos Matos n.ํㅜ 3; Santiago dos Velhos; 2630-533 \\ Arruda dos Vinhos; Portugal \\ Correo electrónico: crbaixinho@esel.pt \\ Recibido: 09/06/2018; Aceptado: 12/10/2018
}

\section{ABSTRACT}

This study aimed to identify the therapeutic use of wine, in the period between 1701 and 1800, in Portugal, and characterize the nursing care in the preparation and administration of this therapy. The historical method was used. Data collection was done by consulting the primary sources in libraries, with especial emphasis on the library of the Royal Palace of Mafra. The ethical procedures of historical research were taken into account. Wine has been present in the life of man since its earliest days. It was an important element of life and festivities, but also a therapeutic element for the cure of diseases and preparation for eternity. During the eighteenth century it was widely used as a therapy for the treatment of different diseases, including aesthetic treatments. These preparations were carried out in the Boticas, and the nurses were in charge of its administration, as well as in charge of preparing the baths, sheets and cloths of herbs for the application of this medication. Therapy by wine was prescribed by the physician, prepared in the public pharmacies, or in the convents' nurseries, and administered by the nurses, who ensured the effectiveness of the treatment.

Keywords: History, nursing, patients, wine, XVIII century. 


\section{RESUMO}

Este estudo teve por objetivos identificar a utilização terapêutica do vinho, no período de 1701-1800, em Portugal, e caracterizar os cuidados de enfermagem na preparação e administração desta terapêutica. Recorreuse ao método histórico. A colheita de dados foi feita com consulta a fontes primárias existentes em bibliotecas, com especial ênfase na biblioteca do Palácio Real de Mafra. Foram tidos em conta os procedimentos éticos inerentes a este tipo de pesquisa. $\mathrm{O}$ vinho esteve presente na vida do homem desde os seus primórdios. Foi um elemento importante da vida e das festividades, mas também elemento terapêutico para a cura da doença e na preparação para a eternidade. Durante o século XVIII era amplamente utilizado como terapêutica para o tratamento de diferentes enfermidades, incluindo os tratamentos estéticos. Estas preparações eram realizadas nas Boticas, estando a sua administração a cargo dos enfermeiros, que preparavam banhos, lençóis e panos de ervas para a sua aplicação. A terapêutica pelo vinho era prescrita pelo médico, preparada nas boticas quer públicas, quer na das enfermarias dos conventos, e administrada pelos enfermeiros, que zelavam pela eficácia do tratamento.

Palavras chave: História, enfermagem, pacientes, vinho, século XVIII.

\section{RESUMEN}

Este estudio tuvo como objetivo identificar la utilización terapéutica del vino en el período entre 1701 y 1800, en Portugal, y caracterizar los cuidados de enfermería en la preparación y administración de esta terapéutica. Se ha usado el método histórico. La cosecha de datos se hizo a través de la consulta de fuentes primarias existentes en bibliotecas, con especial énfasis para la biblioteca del Palacio Real de Mafra. Se han tenido en cuenta los procedimientos éticos inherentes a este tipo de pesquisa. El vino ha estado presente en la vida del ser humano desde sus principios. Fue un elemento importante de la vida y de las festividades, pero también un elemento terapéutico para la cura de la enfermedad y para la preparación de la eternidad. Durante el siglo XVIII era ampliamente usado como terapéutica para el tratamiento de diferentes enfermedades, incluyendo los tratamientos estéticos. Estas preparaciones eran realizadas en las Boticas, donde eran administradas por los enfermeros, quienes preparaban baños, sábanas y pañuelos de hierbas para su aplicación. La terapéutica del vino era prescrita por el médico, preparada en las boticas, sea en las públicas, sea en las boticas de las enfermerías de los conventos, y administrada por los enfermeros, quienes cuidaban de la eficacia del tratamiento.

Palabras clave: Historia, enfermería, pacientes, vino, siglo XVIII.

\section{INTRODUÇÃO}

É pouco provável que se consiga estabelecer quem foram os primeiros produtores de vinho (Estreicher, 2006). As escavações efetuadas na Turquia, em Catal Hüyük -considerada a primeira das cidades da humanidade- revelaram sementes de uvas da Idade da Pedra, cerca de 8000 A.C. (Johnson, 1989). Calcula-se que entre 80007000AC o homem dominava a cultura da vinha na região entre o Mar Negro e o Mar Cáspio. Os vestígios arqueológicos encontrados na Geórgia (7000-5000AC), as análises de carbono (Johnson, 1989; Estreicher, 2006) e a descoberta do Kwervri (jarro de argila) com vestígios de cristais de ácido tartárico, levam os historiadores a 
inferir que seria, provavelmente, aqui que foram cultivadas as primeiras sementes de uva, o que faz desta região o berço do cultivo de vinha e da produção de vinho (Johnson, 1989). Os investigadores colocam também a hipótese destes povos utilizarem galhos de videira para adorno das sepulturas (Johnson, 1989). O comércio pode ter sido o grande impulsionador da propagação do vinho das remotas aldeias neolíticas isoladas para todo o Oriente e posteriormente para a região mediterrânea (Estreicher, 2006). Nas civilizações antigas, não só mediterrâneas, mas também nos países árabes e asiáticos, contam-se 36 Deuses do vinho (Estreicher, 2006). Os mais conhecidos são Baco em Roma, Dionísio na Grécia e Osíris no Egito.

$O$ vinho era parte integrante da cultura dos antigos egípcios (Estreicher, 2006; Fonseca, Jané \& Ibrahim, 2012) que criaram as ânforas. Os melhores vinhos egípcios eram importados pelos gregos e fenícios e envelheciam alguns anos nas ânforas antes de serem consumidos. Este éter dos deuses era a bebida das elites (Estreicher, 2006), consumida maioritariamente pelas classes elevadas e família real (Fonseca, Jané \& Ibrahim, 2012). Por exemplo Tutankhamen gostava de vinho vermelho (Estreicher, 2006), os pobres bebiam cerveja (Johnson, 1989; Estreicher, 2006).

Para além do consumo, o vinho tinha outras utilidades: era oferecido nos rituais nos templos pelo faraó e pelos sacerdotes para o reforço do poder real (Fonseca, Jané \& Ibrahim, 2012). A partir da 5. - Dinastia passou a acompanhar também os mortos, para a vida no além, sendo a principal bebida do faraó depois da sua ascensão aos céus (Fonseca, Jané \& Ibrahim, 2012). Dessa forma as ânforas com vinho eram enterradas como oferendas funerárias (Fonseca, Jané \& Ibrahim, 2012). No túmulo de Scorpion foram encontradas 700 ânforas com vinho, o que sugere que esta era uma importante parte da vida. Essa importância era tão relevante que passou a acompanhar a pessoa na sua passagem para o além (Estreicher, 2006; Fonseca, Jané \& Ibrahim, 2012). Nas necrópoles reais de Abdju e Saqqara (Egipto), as jarras de cerâmica que continham o vinho tinham um metro de altura, tampa de barro e estavam estampadas com o selo real (Fonseca, Jané \& Ibrahim, 2012).

$\mathrm{Na}$ medicina o vinho era utilizado como ingrediente principal ou como excipiente para dissolver compostos sólidos (Estreicher, 2006; Fonseca, Jané \& Ibrahim, 2012). No Papiro de Ebers o vinho é utilizado como estimulante do apetite (aperitivo) e como anti-helmíntico (Fonseca, Jané \& Ibrahim, 2012). No Antigo Testamento, no livro do Gênesis, capítulo 9, versículo 20, há referencia ao cultivo da Terra e à plantação de uma vinha por Noé (Biblia, 1980), o qual parecia apreciar a bebida resultante da fermentação dos seus frutos. Também os hititas (2000AC), que ocupavam a região da Turquia, criaram recipientes próprios para o deguste do vinho (cálices e frascos feitos em ouro e com formas diversas) (Johnson, 1989). Vários textos antigos faz menção aos vinhos e vinha. O Código de Hammurabi (1795-1750 AC), apresenta menção a tavernas, propriedade de mulheres e ao comércio do vinho (Estreicher, 2006), todavia no código é claro que as sacerdotisas estavam proibidas de abrir ou de entrar numa casa de vinho, ao que parece para que permanecessem ritualmente puras. Caso não cumprissem com o estabelecido corriam o risco de serem queimadas vivas (Johnson, 1989).

Os povos que viviam na região da Grécia apreciavam o vinho. A adega do rei Nestor tinha capacidade para 6000 litros de vinho, armazenado em jarras (Johnson, 1989). Nas 
suas obras Homero faz diversas citações e descrições sobre o vinho, aparentemente a uva era seca ao sol para dar vinhos doces (Johnson, 1989). Estes povos refinaram a arte vinícola produzindo vinhos doces e duradouros (Estreicher, 2006). Utilizavam o vinho nas celebrações e convívios, organizando festivais para o seu consumo (Estreicher, 2006). Também o utilizavam como elemento terapêutico. Hipócrates fez várias observações sobre as propriedades medicinais do vinho (Johnson, 1989; Estreicher, 2006), aconselhava que às crianças o vinho deveria ser dado diluído (Estreicher, 2006).

Durante décadas as ilhas gregas foram os principais exportadores de vinho (Johnson, 1989). É este povo que introduz o vinho no sul da Itália (Johnson, 1989; Estreicher, 2006). A norte essa proeza coube aos etruscos (Johnson, 1989).

Na era do imperador Augusto os romanos exportavam vinho para a Grécia, Macedónia e Dalmácia (Johnson, 1989). Na produção de vinho Pompeia teve um lugar de destaque, sendo a maior fornecedora de vinhos para Roma, com a sua destruição em 79AC houve rapidamente a (re)plantação de vinha por outras regiões (Johnson, 1989). Os romanos plantaram vinhas em todos os seus domínios. Em Portugal nas Ruínas romanas de Milreu ou Ruínas de Estói, concelho de Faro, datadas do século I da era cristã há vestígios romanos do cultivo de vinho. Nestas ruínas apareceu um busto de Dionísio, divindade ligada ao vinho, que tinha na cabeça uma grinalda de parras e cachos de uvas (Jonnhnson, 1989; Estreicher, 2006). O modo de produção era semelhante ao da vizinha Andaluzia (Estreicher, 2006). A expansão das vinhas só voltou a acontecer 1000 anos após a queda de Roma, quando os espanhóis e portugueses chegaram à América central e do sul (Estreicher, 2006).
Após a queda do império romano a produção de vinho permaneceu em latência (Johnson, 1989), até à idade média. A presença do vinho na liturgia como símbolo do sangue de Cristo levou a que a Igreja tivesse um papel importante no seu cultivo, extração e preparação, sendo ela própria proprietária de extensas vinhas (Estreicher, 2006). A relação da igreja com os hospitais medievais também pode ser associada ao vinho. Um célebre caso de um hospital que surge pelas mãos de um proprietário de vinhas é o Hôtel-Dieu ou Hospice de Beaune, fundado em 1443 DC, até hoje mantido pelas vendas de vinho (Johnson, 1989). Durante a antiguidade e idade média, por toda a Europa, o vinho foi uma bebida de eleição para acompanhar refeições, marcar festas e como tratamento coadjuvante de algumas enfermidades.

São objetivos deste trabalho identificar a utilização terapêutica do vinho em Portugal, no período de 1701-1800, e caracterizar os cuidados de enfermagem na preparação e aplicação desta terapêutica no mesmo período histórico.

\section{MÉTODO}

Este estudo recorreu ao método histórico para responder às questões de investigação: Qual a utilização terapêutica do vinho, no período de 1701-1800, em Portugal? e Quais os cuidados de Enfermagem na aplicação desta terapêutica, no período em estudo?

A metodologia histórico foi utilizada com a finalidade de preencher os vazios dos fatos e dos acontecimentos, reconstruindo-os, de modo a assegurar a percepção da continuidade e do entrelaçamento dos fenómenos (Boas, 2004). A colheita de dados foi feita com consulta a fontes primárias existentes em bibliotecas, com especial ênfase na biblioteca do Palácio Real de 
Mafra, que tem um valioso acervo com cerca de 36.000 obras.

Foram critérios de inclusão das fontes primárias: livros, documentos legais, regulamentos de ordem religiosas com atividade em enfermarias de conventos e outras fontes datadas entre 1701-1800 que descrevam a utilização terapêutica do vinho aos enfermos e/ou os cuidados de enfermagem na sua preparação e/ou administração.

Não foi pedido aprovação por um Comitê de Ética por não se tratar de uma pesquisa com seres humanos, todavia foram tidos em conta os princípios éticos a que obriga a pesquisa histórica. $\mathrm{O}$ desenvolvimento da pesquisa em história da enfermagem depende da qualidade das fontes documentais e dos esforços do investigador, que deve proteger a memória da profissão, mediante a recuperação, preservação e produção de fontes históricas (Peres \& Santos, 2015). Desde a concepção do projeto, à pesquisa nas fontes primárias, à análise dos achados e elaboração do artigo final houve a preocupação de construir uma versão histórica consistente.

\section{RESULTADOS}

A pesquisa permitiu identificar sete fontes primárias que permitem dar resposta à questão de investigação (Figura 1).

FIGURA 1: Fontes Primárias constituintes da amostra bibliográfica. Lisboa; 2016

\begin{tabular}{|l|l|l|l|}
\hline \multicolumn{1}{|c|}{ Nome do documento } & \multicolumn{1}{|c|}{ Autor } & Ano & \multicolumn{1}{|c|}{ Tipo de Documento } \\
\hline CURSO CHIMICO & Nicolas Lemetry & 1721 & Livro de cirurgia e medicina \\
\hline $\begin{array}{l}\text { Castello Forte contra todas as } \\
\text { infirmidades que pereguem o } \\
\text { corpo humano, E Thesouro } \\
\text { universal, aonde se acharàõ os } \\
\text { remedios para ellas }\end{array}$ & João Lopes Correa & 1723 & Livro médico \\
\hline $\begin{array}{l}\text { Pharmacopea Lusitana } \\
\text { augmentada }\end{array}$ & $\begin{array}{l}\text { Caetano de Santo } \\
\text { António }\end{array}$ & 1725 & Farmacopeia \\
\hline Cirurgia reformada & Feliciano de Almeyda & 1738 & Livro de cirurgia \\
\hline $\begin{array}{l}\text { Postilla Religiosa de } \\
\text { Santiago }\end{array}$ & 1741 & Livro de Enfermagem \\
\hline $\begin{array}{l}\text { Medicina Lusitana, Socorro } \\
\text { Delphico. Aos clamores da } \\
\text { natureza humana, para total } \\
\text { profligação de seus males }\end{array}$ & $\begin{array}{l}\text { Francisco da Fonseca } \\
\text { Henriques }\end{array}$ & 1750 & Livro médico \\
\hline $\begin{array}{l}\text { Pharmacopea Tubalense } \\
\text { Canoel Rodrigues }\end{array}$ & 1751 & Farmacopeia \\
\hline
\end{tabular}

Duas fontes são farmacopeias (Santo António, 1725; Coelho, 1751), duas são livros médicos (Correa, 1723; Henriques, 1750)), duas livros de cirurgia (Lemetry, 1721; Almeyda, 1738) e um manual de enfermagem (Santiago, 1741), o qual é até hoje a primeira obra, conhecida em Portugal, redigida por um frade enfermeiro da Ordem Hospitaleira de São João de Deus, para a formação dos seus noviços, também eles enfermeiros (Santiago, 1741).

O Livro CURSO CHIMICO é o único livro que não é português (Lemetry, 1721). O autor é Nicolas Lemetry, francês, doutor em 


\section{Cultura de los Cuidados}

medicina, da academia real das ciências. Foi incluído na amostra porque, à época, muitos dos livros médicos eram franceses ou castelhanos e havia uma forte influência francófona nos cuidados de saúde em Portugal.

A análise documental permitiu identificar que o vinho era utilizado como elemento terapêutico para uma grande diversidade de patologias. Para além de remédio primário servia para a diluição de outros produtos.

$\mathrm{Na}$ próxima figura (Figura 2) está sintetizado os tipos de vinhos usados e as suas indicações terapêuticas.

FIGURA 2: Tipos de vinho e indicações terapêuticas. Lisboa; 2016

\begin{tabular}{|c|c|}
\hline Tipo de vinho & Indicações terapêuticas \\
\hline Vinho Aloético-alkalino & $\begin{array}{l}\text { Tratamento de estados de histeria; icterícia; obstrução de glândulas e } \\
\text { ductos biliares; alterações linfáticas e nas caquexias uterinas }\end{array}$ \\
\hline Vinho Amargo & Antipirético \\
\hline Vinho Anti-scorbutico & Efeito diurético \\
\hline Vinho Chalebiado & $\begin{array}{l}\text { Indicado para as obstruções das vísceras; icterícia } \\
\text { Antipirético }\end{array}$ \\
\hline Vinho de Cypó & Antipirético e tratamento de abcessos estomacais \\
\hline $\begin{array}{l}\text { Unguento Anodino } \\
\text { (vinagre de fezes de ouro) }\end{array}$ & Para controlo da dor local; tratamento das hemorroidas e do prurido \\
\hline Vinho emetico & Vomitório \\
\hline Vinho purgante & Purgava os humores \\
\hline Vinho estitico & $\begin{array}{l}\text { Feito com vinho vermelho tinha funções estéticas para apertar e } \\
\text { confortar zonas de pele laxas e para os achaques em que há edema das } \\
\text { pernas precedido de humor frio }\end{array}$ \\
\hline
\end{tabular}

Adaptado das Farmacopeia Lusitana (Santo António, 1725) e Tubalense (Coelho, 1751)

A utilização terapêutica do vinho era acompanhada de várias recomendações como as indicações de administração face à doença do enfermo. Por exemplo, os feridos só tomavam vinho em três situações "quando ouver summa fraqueza, o segúdo he, quando houver animi diliquium, o terceiro he, quando o ferido tiver lançado muito sangue, ou seja defluxo, ou da ferida" (Correa, 1723, p. 9). Nas feridas incisas o vinho não era aconselhável "salvo o ferido for homem velho, ou estiver demasiadamente fraco, porque então lhe mandarão dar sobre a comida huma, ou duas colheres de vinho" (Almeyda, 1738, p. 41). A posologia era individualizada em função da patologia: “Aconselha-se para a dor de dentes, febres malignas, peste, 2 a 3 gotas de azeite de clavos "en água de torongial, ò otro licoi apropriado" (Lemetry, 1721, p. 54) e existem indicações expressas para o que pode acompanhar a toma do vinho, por exemplo, o "vinho generoso conforta o estômago melhor que tudo, principalmente tomado-o com pão de ló, ou com pão commum, porque assim detem-se mais tempo no estômago, do que bebendose, e por isto o corrobora melhor" (Henriques, 1750, p. 375).

Era contraindicado administrar a terapêutica: "Aquelles, que sentem dano na cabeça depois que bebem vinho; e se o fluxo ainda correr, se não deve conceder, né tambem àquelles, que depois que bebem 
vinho, vem cousas estranhas diante dos olhos, porque a estes lhes fará grande prejuízo" (Correa, 1723, p. 174). As indicações para a administração desta terapêutica, pelos enfermeiros, estão bem explicitas na Postilla Religiosa (Santiago, 1741). Na Figura 3 sintetizam-se o modo de aplicação da terapêutica com vinho e os principais cuidados de enfermagem.

FIGURA 3: Preparação e aplicação do vinho pelos enfermeiros. Lisboa; 2016

\begin{tabular}{|l|l|}
\hline Modo de aplicação do vinho & \multicolumn{1}{|c|}{ Cuidados de Enfermagem } \\
\hline \multirow{2}{*}{ Lençóis } & $\begin{array}{l}\text { Ensopar os lençóis, torcendo-os bem. Com o lençol } \\
\text { humedecido embrulhar o enfermo, da cabeça aos pés } \\
\text { cobrindo, de seguida, tapar com mais roupa. } \\
\text { Manter a terapêutica durante o tempo prescrito pelo médico. }\end{array}$ \\
\hline \multirow{3}{*}{ Panhos de Ervas } & $\begin{array}{l}\text { Colocar as ervas no vinho (de acordo com o tipo de vinho a } \\
\text { preparar), previamente aquecido, durante algumas horas para } \\
\text { que este fique robusto e difícil de avinagrar. Mergulhar o } \\
\text { enfermo no banho, ficando de molho várias horas. }\end{array}$ \\
\hline & $\begin{array}{l}\text { Cozer o vinho tinto puro, ou misturado, juntamente com } \\
\text { algumas plantas que absorvam o fluxo (murta, flor de romã, } \\
\text { nozes de cipreste...) de seguida ensopar os panos e colocar } \\
\text { sobre o ventre do enfermo. }\end{array}$ \\
\hline
\end{tabular}

FuENTE: Adaptado da Postilla Religiosa (Santiago, 1741)

Há indicações precisas para não haver erro na administração dos remédios "(...) muito particular cuidado nos números (...), para que não haja equivocação na applicação" (Santiago, 1741, p. 76), sendo necessário que o enfermeiro atestar a qualidade dos medicamentos, a cor, o cheiro, a hora e a prescrição do médico (Santiago, 1741), estas orientações estendiam-se à aplicação do vinho.

\section{DISCUSSÃO}

Seis das fontes primárias foram identificadas na biblioteca do Palácio Real de Mafra. O Real Palácio e Convento de Mafra, a par do Hospital Real de Todos os Santos, assumiu no século XVIII uma importância ímpar na assistência aos enfermos, em Portugal, o que no caso do palácio se justifica pela vasta coleção literária da sua biblioteca na área da saúde a qual muito provavelmente orientou a prática dos enfermeiros nas enfermarias do convento, bem como dos boticários, físicos e cirurgiões que aí exerceram. Em Portugal, a medicina monástica assumiu desde o inicio do reino um papel preponderante na prestação de cuidados à população, com uma atuação eficiente conforme os padrões teóricos e práticos do período (Santos, 2012). O Real Palácio de Mafra foi mandado construir por D. João V em 1717, é atualmente o mais importante monumento do barroco em Portugal. Foi inicialmente concebido como convento para albergar 13 frades, da Ordem de S. Francisco (Regrantes Arrábidos), mas o projeto sofreu várias alterações. A obra terminou num edifício com $40000 \mathrm{~m}^{2}$ que integra o Palácio Real, a basílica e um convento com capacidade para 300 frades (Conceição, 1820). No edifício original do convento existiam três enfermarias: Enfermaria dos 
Convalescentes, Enfermaria dos Noviços e Enfermaria dos Doentes Graves. Existia ainda uma pequena sala destinada a "enfermaria dos doidos" (Bandeira, 1734).

No dia 22 de outubro de 1730 ingressaram no convento de Mafra 328 frades arrábidos, oriundos de diversos conventos da região, que foram entretanto extintos (Conceição, 1820). Em 1771, no reinado de D. José, estes religiosos foram enviados para outro convento e os Cónegos Regrantes de Santo Agostinho foram transferidos para o Convento de Mafra (Conceição, 1820) e ai permanecem até 1791, altura em que regressam os Franciscanos da Província de Santa Maria da Arrábida, a pedido da Rainha D. Maria I. Estes abandonaram definitivamente o convento em 1833 ao aproximar-se um destacamento de cavalaria liberal, ficando o convento a saque. Regressaram a ele novamente os Cónegos Regrantes de Santo Agostinho até à extinção das ordens religiosas após 1834 (Carvalho, 1948). De acordo com os Estatutos da Ordem de S. Francisco -uma das ordens religiosas que ocupou o Real Convento- o vinho era um bem que fazia parte do quotidiano (S. Francisco, 1698), apesar da ordem não querer que nos seus conventos se faça vinho, permitia que "dentro das nossas cercas haver parreyras \& alguma vinha pequena, para se comerem \& pendurarem algumas uvas" (S. Francisco, 1698, p. 81).

Uma consulta detalhada à relação de alimentos que eram adquiridos permite verificar que o vinho era comprado para ser servido durante as refeições, mas também para o uso na Botica (Gorjão, 2015). O "vinho, guardado em armazém próprio e a chave do armazém do vinho estará sempre na mão do fiel o qual o suposto cálculo de quanto se gasta cada dia/dará ao refeitoreiro a porção correspondente" (Gorjão, 2015, p. 83).
Esta análise permite-nos inferir que as receitas que constam na Farmacopeia Lusitana (Santo António, 1725) e Tubalense (Coelho, 1751), e que orientavam a atividade dos Boticários nesta e noutras enfermarias pelo país eram aplicadas como terapêutica, com a finalidade de curar enfermidades tão diversas, como a icterícia, a obstrução das glândulas, controlo da dor e até das hemorroidas (Santo António, 1725; Coelho, 1751). Importa contextualizar que a teoria humoral, desenvolvida por Hipócrates, que tenta uma explicação da doença, e consequentemente da cura, através do equilíbrio entre o sangue, a fleuma, a bílis amarela e a bílis negra (Sevalho, 1993), continua a ser uma teoria vigente neste período. Deste modo, a utilização do vinho como terapêutica tenta promover o equilíbrio perdido dos humores corporais.

Os enfermeiros asseguravam cuidados na preparação e aplicação dos remédios (Santiago, 1741). Assim eles embebiam os lençóis e panos em vinho e outras ervas e o enfermo era completamente envolvido nos lençóis ensopados de vinho para, por exemplo, diminuir a produção excessiva de secreções (Santiago, 1741; Baixinho, Mariano, Vilela, Tavares, Cruz \& Moreira, 2016). Se bem que na Postilla Religiosa os usos do vinho apareçam associados à inibição das secreções e ao tratamento de patologias relacionadas com a diarreia (Santiago, 1741), no caso de corrompido o aquecimento e avinagrado, esta bebida seria útil na promoção de secreções (Santiago, 1741; Baixinho, et al., 2016).

Outra possibilidade terapêutica era cozer o vinho com ervas aromáticas, durante algumas horas, até que ficasse denso e difícil de avinagrar, e depois mergulhar o doente como se de um banho se tratasse; ou então, cozer o vinho tinto com plantas e ensopar em panos, que eram posteriormente 
colocados no ventre da pessoa afetada pelo mal (Baixinho, et al., 2016). Estes, como outros remédios, tinham de ser aplicados aos enfermos pela mão dos próprios enfermeiros que garantiam a segurança na identificação do tipo de vinho, cor, qualidade, quantidade e cheiro, porque, como adverte Frei Diogo Santiago nas boticas, muitas vezes, acontece porem-se os números errados e isso só poderia ser remediado com a experiência na administração da terapêutica (Santiago, 1741).

\section{CONCLUSÕES}

$\mathrm{Na}$ pesquisa histórica efetuada identificaram-se sete fontes documentais primárias que permitiram dar reposta às duas questões de investigação formuladas.

No período em análise (1701-1800) o vinho era considerado um remédio eficaz para o tratamento de várias patologias e um solvente de eleição para outros componentes farmacológicos utilizados nas Boticas. Os enfermeiros preparavam e administravam esta terapêutica de acordo com a prescrição médica. Os modos de aplicação preferenciais era através de banhos, lençóis ou panos de ervas embebidos neste liquido, de modo a controlar as secreções, diarreias e outros distúrbios gastrointestinais, queimaduras e inflamações, entre outros. O fim último do cuidado na administração da terapêutica era o equilíbrio dos quatro humores. Para que isto fosse possível o enfermeiro tinha de seguir uma série de regras de segurança que garantissem a qualidade do tratamento, a integridade e conservação do remédio, a administração segura e a vigilância da reação do organismo à terapêutica.

Os resultados deste estudo histórico não podem ser extrapolados para a realidade dos cuidados de enfermagem nos dias de hoje, mas é uma contributo para aumentar o conhecimento do nosso passado e com isso enaltecer as funções do enfermeiro e o contributo dos cuidados, à época, para a saúde e segurança dos clientes.

\section{FONTES PRIMARIAS}

- Almeyda, F. (1738). Cirurgia reformada. Lisboa Occidental: Na Officina de Antonio Pedrozo Galram.

- Bandeira, G,C. (1734). Relação do Convento de Santo Antônio de Mafra: 1730 a 1744. Ms. Mafra: colecção particular. Manuscrito na propriedade de E. Medeiros.

- Coelho, M.R. (1751). Pharmacopea Tubalense ChimicoGalenica. Lisboa: Na Officina de Jozé da Sylva da Natividade.

- Conceição, F.C. (1820). Gabinete Histórico, Tomo VIII. Lisboa: Torre do Tombo.

- Correa, J.L. (1723). Castello Forte contra todas as infirmidades que pereguem o corpo humano, E Thesouro universal, aonde se acharào os remedios para ellas. Lisboa Occidental: Officina da Musica.

- Henriques, F.F. (1750). Medicina Lusitana, Socorro Delphico. Aos clamores da natureza humana, para total profligação de seus males. Porto: Na Officina Episcopal de Manoel Pedroso Coimbra.

- Lemetry, N. (1721). Curso Chimico, en el qual se enseña el modo de hazer las operaciones mas usuales en la medicina, com reflexiones sobre cada operacion, para la instruccion de los que se quieren aplicar a esta ciência (3. ed.). Madrid: Por Manuel Romàn, Impressor de Libros, en la Calle del Duque de Alva.

- Santiago, D. (1741). Postilla religiosa e arte dos enfermeiros, guarnecida com eruditos conceitos de diversos authores, facundos, moraes, e escriturários. Lisboa: Lisboa Occidental.

- Santo Antonio, C. (1725). Pharmacopea Lusitana augmentada. Lisboa Occidental. Na Officina de Francisco Xavier de Andrade.

- Francisco, S. (1698). Estatutos da Província de Santa Maria de Arrábida da mais perfeyta observância de nosso Seraphico Padre S. Francisco. Lisboa: Na Officina de Miguel Deslandes, Impressor de Sua Majestade. 


\section{REFERÊNCIAS}

- Baixinho, C.L., Mariano, E.M., Vilela, J.F.F., Tavares, M.R.S., Cruz, M.C.V.G., Moreira, M.C. (2016). Os poderes curativos do vinho no século XVIII. Rev Referência, 4(9), 249.

- Bíblia. (1980). Português. Bíblia Sagrada. Rio de Janeiro: Encyclopaedia Britannica.

- Boas, F. (2004). Os métodos da etnologia. In: Castro (Org.). Antropologia Cultural (6. ed.) Rio de Janeiro: Zahar.

- Carvalho, A. A. A. (1948). Antiga Botica do Convento de Mafra e o Material Atualmente Existente. (1. ${ }^{a}$ edição). Mafra: Coimbra Editora Lda.

- Estreicher, S.K. (2006). WINE: From Neolithic Times to the 21st Century. New York: Algora Publishing.

- Fonseca, S., Jané, M.R.G., Ibrahim, M. (2012). O vinho no Antigo Egito: uma história mediterrânea. Mundo Antigo,1(1), 139-55.
- Gorjão, S. (2015). Princípios e Fundação do Real Convento de Mafra, e sua grandeza, e sua sustentação, e luxo, etc. Livro das Pitanças. 1763-1770. Mafra: Associação dos Amigos do Convento de Mafra.

- Johnson, H. (1989). The Story of Wine. Londres: Mitchell-Beazley.

- Peres, M.A.A., Santos, T.C.F. (2015). Ethics in Historical Research in Nursing and Health Perspective to Scientific Integrity. Hist enferm Rev eletronica, 6(1), 4-7.

- Santos, D.O.A. (2012). Aproximações à medicina monástica em Portugal na Idade Média. História ( $S$. Paulo),31(1), 47-64.

- Sevalho, G. (1993). Uma abordagem histórica das representações sociais de saúde e doença. Cadernos de Saúde Pública, 9, 349-63. 